\title{
Efeitos do trabalho sobre a saúde de adolescentes
}

\author{
Effects of work on the health of adolescents
}

Frida M arina Fischer 1

Denize Cristina Oliveira 2

Liliane Reis Teixeira 1

M aria Cristina Triguero Veloz Teixeira 1

M ariana Almeida do Amaral 1

1 Departamento de Saúde Ambiental, Faculdade de Saúde Pública, USP. Av. Dr. Arnaldo 715, 01246-904, São Paulo SP. fmfische@usp.br 2 Departamento de Fundamentos da Enfermagem, Faculdade de Enfermagem, UERJ.
Abstract This study evaluated life and work conditions and their impact on the health and psychological development of adolescents. A number of 354 high school students, 14 to 18 years old, studying during evening period took part in this study. Data were collected using free evocation technique and questionnaires. Data on sleep during the weekdays were obtained using questionnaires, filled out by students regarding life and work conditions, health symptoms and illness. Data were analyzed with software EVOC 2000 for the social representations, and T-Student, AN OVA, M ann-Whitney e Kruskal-Wallis tests were employed for analyze health and sleep conditions. Differences were found among worker students who reported shorter mean sleep durations and: males, feeling sleepy at work and classes, referring to tougher psychological demands at work, working as salesperson, earning more than 1 minimum monthly wage, working more than 6 hours per day or 20 hours per week, working in noisy environment or polluted with gases and vapors. The representation of work among teen workers point a contradiction between recognizing work as a moral positive value to psychosocial development and identity construction, and the negative consequences due to precocious exposure to physical and psychological workloads.

Key words Teen workers, $\mathrm{H}$ ealth conditions, Sleep duration, Social representations
Resumo 0 estudo analisa conseqüências do trabalho para as condições de vida, saúde e de senvolvimento psicossocial de adolescentes. Participaram do estudo 354 estudantes de 14 a 18 anos, do ensino médio, período noturno. $\mathrm{A}$ análise das representações foi realizada a partir da coleta de evocações livres. Os dados sobre sono foram obtidos por mei o de questionários, sobre auto-percepções acerca das condi ções de vida e trabalho, sintomas de saúde e doenças. A análise de dados foi realizada com o software EVOC 2000 eSPSS. Constataram-se diferenças significativas na duração média de sono entre os adolescentes: os trabal hadores relataram menores médias de duração de sono. Entre os trabalhadores, referiram dormir menos os que sentem sono no trabalho e nas aulas, têm maiores exigências psicológicas no trabalho, ganham acima de 1 salário mínimo mensal, jornadas acima de 6 horas diárias ou acima de 20 horas semanais, trabalham em local baruIhento e com presença de gases e vapores. As representações do trabalho entre os jovens apontam contradição entre o seu reconhecimento como valor moral positivo para o desenvolvimento psicossocial e a construção da identidade, eas conseqüências negativas decorrentes da exposição a cargas físicas e psi cológicas precocemente.

Palavras-chave Trabal ho de adolescentes, Condi ções de saúde, Duração de sono, Representações sociais 


\section{Introdução}

A presença de adolescentes na força de trabaIho tem sido encorajada pela sociedade, inclusi ve sendo prática incentivada através de política governamental expressa pelo Programa Primeiro Emprego. 0 ingresso precoce de jovens no trabalho é legalizado pela legisl ação brasileira.

0 trabalho desenvolvido precocemente por adolescentes pode ser fator decisivo em suas vidas, podendo ter conseqüências positivas e também negativas ao seu desenvolvimento físico e psicossocial, especialmente em função da competição que se estabelece entre as atividades de trabalho extra-escolar ou domiciliar e as atividades escolares, de esporte e lazer, portanto aquelas que possibilitam um meio saudável de formação psicológica e social do jovem. Em metrópoles como São Paulo muitos adolescentes que freqüentam o ensino público precisam trabalhar para ajudar a compor o orçamento familiar, colocando, muitas vezes, a atividade escolar em segundo plano (Fischer \& Oliveira, 2003a).

Em nosso país, segundo dados do censo de 2000, cerca de 9 milhões de adolescentes de 15 a 19 anos estão inseridos no mercado de trabaIho (IBGE, 2000). Para os adolescentes, o trabalho tem um significado mais profundo, ligado intimamente com a maturidade e a emancipação econômica (M ielnik, 1987). A situação socioeconômica em que se encontra a família é um outro motivo que pode levar 0 adolescente ao trabalho, tendo consistente influência nas suas decisões, até mesmo na freqüência escolar. Esse fato mantém o círculo vicioso da pobreza, fazendo com que crianças e adolescentes tornem-se adultos que pouco poderão passar a seus filhos, além da herança da miséria e da marginalização (Abreu, 2002).

0 trabalho precoce, geralmente, promove efeitos negativos no desenvolvimento físico e educacional, impedindo o jovem de dedicarse $a$ atividades extracurriculares, como atividades lúdicas e sociais próprias da idade, trazendo isolamento dos jovens entre seus pares e familiares, bem como sendo responsável pelo atraso escolar. Esses danos são de difícil superação porque há um tempo certo para vivenciar as várias etapas da formação da adolescência (O livei ra et al., 2001). I gualmente grave, são as doenças e acidentes decorrentes das atividades realizadas no trabal ho. $\mathrm{Na}$ condição de aprendiz, o trabalho dos adolescentes tem sido legitimado, mas freqüentemente prevalece 0 aspecto produtivo sobre o educativo, além de nem sempre haver condições apropriadas de saúde e segurança no trabalho (Fischer et al., 2003b, Kassouf et al., 2001).

Os aprendizes, usualmente, desconhecem seus direitos trabalhistas, submetendo-se a situações arriscadas, insalubres e inadequadas, a salários aviltantes, trabalhando horas-extras, não se protegendo adequadamente dos riscose das péssimas condições de trabalho em geral (Fischer et al., 2000, 2003a, b; Parker, 1997).

M esmo não sendo a jornada de trabal ho coincidente com o horário escolar, os estudos fora desse horário ficam prejudicados, afetando o rendimento escolar, conforme observado por Oliveira et al. (2001) em estudo com adolescentes de duas cidades do interior do Estado de São Paulo. Estudos conduzidos por Andrade (1997) e Carskadon (1989 e 1990, citado por NIOSH, 1997) mostraram que o sono dos adolescentes fica prejudicado devido aos horários de entrada na escola eà fadiga causada pelo trabal ho, além de aumentar os riscos de acidentes decorrentes da sonolência durante o trabaIho. Para Fischer et al. (2000), o padrão do ciclo vigília-sono típico de adolescentes (dormir e acordar em horários mais tardios) fica alterado pelo fato de os jovens trabal harem e estudarem. Essa dupla jornada obriga os adolescentes a acordarem muito cedo, e irem dormir tarde, contribuindo para uma redução crônica da duração do seu sono noturno e pela percepção de cansaço crônico (Vinha et al., 2002). Acrescenta-se a este fato a diminuição no tempo utilizado para realizar as tarefas escolares, impedindo 0 estudante trabalhador de se dedicar com mais afinco aos estudos dentro e fora do período escolar. Os débitos de sono podem ser responsáveis pel os problemas de atenção e concentração durante as aulas, com risco de baixo nível de desempenho escolar, al ém da maior incidência de uso de substâncias estimulantes (Andrade \& M enna-Barreto, 1996; Lack, 1986).

Para análise dessa questão, além da abordagem objetiva dos danos à saúde e ao aproveitamento escolar, igualmente importante é a abordagem das imagens que os atores sociais constroem do trabalho, da relação trabalho-estudo e de si próprios como trabal hadores. Essas imagens, ou representações, acabam por sustentar as práticas sociais que tendem a priorizar o trabal ho sobre o estudo e a manutenção do jovem trabal hador no mercado de trabalho, muitas vezes abandonando a escola precoce- 
mente, ainda num momento de escolarização obrigatória.

Esse processo de exclusão escolar se desenvolve a partir da associação do trabalho a valores morais, a um melhor futuro do que aquele reservado ao jovem em função da sua inserção social, ao esforço pessoal e como forma de contornar problemas urbanos, tais como o envolvimento com drogas ilícitas e a marginalidade, conforme observado em estudo desenvolvido por Oliveira et al. (2001).

Para efeito deste trabalho considera-se que as representações sociais são indispensáveis para a compreensão da dinâmica social e das relações dos indivíduos com seu ambiente social, tornando-se, assim, um elemento essencial na compreensão dos determinantes dos comportamentos e das práticas sociais, particularmente no que se refere à prática do trabalho entre estudantes adolescentes.

Neste trabalho entende-se por representações sociais uma forma de conhecimento socialmente el aborada e compartilhada, que tem uma finalidade prática e contribui para a construção de uma realidade comum a um conjunto social, conforme proposto por Jodelet (1989). U ma representação social é também, segundo o criador da teoria (M oscovici, 1978), um conjunto de conceitos, proposi ções e explicações originadas na vida cotidiana no curso de comunicações interpessoais, que funciona como uma espécie de "teoria do senso comum".

Dado que o presente estudo está vinculado à teoria do núcleo central de Abric (1994), pode-se ressaltar que a mesma propõe que as representações sociais têm seu conteúdo organizado em dois sistemas internos - central e periférico, cada um dos quais possuindo funções e características específicas. Os poucos elementos cognitivos do sistema ou núcleo central, por serem consensuais, mais estáveis, eligados à história do grupo e algo independentes do contexto imediato, conferem à representação o seu significado básico e organizam os demais elementos periféricos. Já o sistema periférico, constituído de um número maior de idéias acerca do objeto representado, faz a interface entre o núcleo central e as situações e práticas concretas da população, incorporando as experiências e histórias individuais dos seus membros e se mostrando, assim, não apenas mais sensível à influência do contexto social imediato, mas também mais flexível na orientação dos comportamentos que nele se desenrolam (Abric, 1994; Sá, 1996; Oliveira, 1996).
0 trabalho do adolescente reveste-se de particularidades que o colocam como questão polêmica e ainda longe de qualquer consenso sobre os seus benefícios e prejuízos, sejam eles à saúde física, à formação da personalidade, à socialização, à escolarização, etc. Sabe-se da carência de dados brasileiros sobreo assunto, particularmente em grandes centros urbanos, na medida em que esse tema apenas recentemente passou a ser discutido e a gerar posições que naturalizam o trabalho na adolescência e outras que o tratam como problema social.

\section{Objetivos}

Avaliar as variáveis associadas às condições de vida, trabalho e à duração de sono entre estudantes do período noturno.

Analisar o conteúdo e a estrutura das representações sociais de estudantes do período noturno sobre o trabalho e a relação trabalho-escola.

\section{Metodologia}

\section{Critérios de inclusão}

Para se obter o grupo de estudantes trabaIhadores foi utilizado como critério a inclusão de todos os adolescentes que referiram trabaIhar. Trabalho foi definido como "toda atividade sistemática em que há uma obrigatoriedade de desenvolver tarefas, em horários e períodos pré-determinados, seja no ambiente domésti$\mathrm{co}$, seja para terceiros, com ou sem remuneração, tendo ou não vínculo empregatício formalizado". Para o grupo de alunos não trabalhadores, foram considerados aquel es que registraram no questionário que nunca trabalharam, ou seja, nunca estiveram expostos aos riscos oferecidos pelo trabalho. Alunos desempregados são aqueles que já estiveram expostos ao trabalho, mas que não estavam trabal hando no momento da pesquisa, embora procurassem emprego.

\section{População participante do estudo}

$\mathrm{N}$ este artigo estão descritos os resultados do estudo realizado entre estudantes que freqüentavam a escola no período das 19 às 22:30 horas, alunos do ensino médio de uma escola pública estadual do município de São Paulo. 
Do total de alunos matriculados nesse período na escola (695), apenas 397 alunos (58\%) eram da faixa etária escolhida para este trabalho (entre 14 e 18 anos completos). Desses, 43 estudantes não participaram do estudo (20 abandonaram a escola, 15 foram transferidos, 4 não aceitaram participar e 4 não foram encontrados), totalizando 354 sujeitos.

\section{Termo de consentimento}

Este estudo foi aprovado pelo Comitê de Ética da Faculdade de Saúde Pública da U SP. Todos os alunos que aceitaram participar do estudo assinaram o Termo de Consentimento Livre e Esclarecido.

\section{Avaliação das condições de vida, saúde e trabalho}

Foram coletadas informações a respeito das condições sociodemográficas, condições de saúde, dores no corpo, horários de dormir e acordar durante a semana e fim de semana, cochilos, queixas relacionadas ao sono, sensação de sonolência e cansaço durante a vigília. Foram obtidas as seguintes informações acerca das variáveis ocupacionais: situação ocupacional, local de trabalho e função exercida, salário, jornada de trabal ho, ambiente de trabal ho e escalas de controle no trabalho (Karasek, 1985).

$\mathrm{Na}$ análise estatística dos dados, para a comparação de duas médias foi utilizado o teste t-Student e na comparação de três ou mais médias foi utilizada a análise de variância a um fator (AN OVA), caso as variâncias dos grupos fossem homogêneas. Quando as variâncias não foram homogêneas, foi utilizado o teste não paramétrico correspondente, a saber, $M$ annWhitney (comparação de duas médias) ou Kruskal-Wallis (comparação de três ou mais médias). As variâncias foram comparadas utilizando o teste de Levène. Em todas as análises foi considerado o nível de significância de 5\%.

\section{Caracterização das representações sociais}

0 estudo das representações sociais foi desenvolvido com a coleta de dados através de evocações livres para a análise estrutural das representações. Foram coletadas evocações livres entre todos os 354 adolescentes, que receberam a instrução de escrever em uma ficha as primeiras cinco palavras ou expressões que lhes ocorressem em relação ao termo indutor trabalhar e estudar.

Para o tratamento dos dados foi utilizado o software Evoc 2000 (Vergès, 2000), que auxiliou na análise do conteúdo e da estrutura da representação social do trabalho a partir da relação trabalho-estudo.

Partiu-se da premissa de que os termos que atendessem, ao mesmo tempo, aos critérios de evocação com maior freqüência e nos primeiros lugares, supostamente teriam uma maior importância no esquema cognitivo do sujeito, ou seja, se configurariam como hipóteses de núcleos centrais da representação social. (Abric, 1994; Sá, 1996; Oliveira, 1996). Considerou-se que as palavras que se situam no quadrante superior esquerdo são, muito provavelmente, elementos do núcleo central da representação estudada; aqueles situados nos quadrantes superiores direito e inferior esquerdo são elementos intermediários, ou primeira e segunda periferia; e aquelas localizadas no quadrante inferior direito são elementos mais claramente perifériCos (Sá, 1996, 1998).

Essas hipóteses serão objeto de verificação da centralidade através da análise de similitude, que é expressa em uma representação gráfica indicando a força das ligações obtidas a partir de um índice de co-ocorrência, entre as categorias construídas a partir dos termos evocados, conforme proposto por Flament (1994; 2001).

\section{Resultados}

\section{Características da população}

Participaram do estudo 354 alunos, sendo $57,3 \%$ dos estudantes do sexo masculino e $42,7 \%$ do sexo feminino. Em relação aos hábitos de vida, $10,7 \%$ dos estudantes fumam regularmente e destes, 58,2\% fumam há mais de 1 ano. Entre os que referiram ingestão de bebida alcoólica ( $n=225$ estudantes ou $63,6 \%$ dos estudados), 50,7\% já esteve de ressaca. Encontramos forte associação entre o hábito de fumar e consumo de bebidas alcoólicas; 95,2\% dos que fumam também bebem $\left(c^{2}<0,01\right)$. Praticam atividade física, $85,3 \%$ dos estudantes, sendo o futebol (35\%) e a dança $(36,9 \%)$ as principais atividades mencionadas. Destes, $30,5 \%$ praticam atividades físicas entre 2 e 3 vezes por semana.

Com relação à saúde, $87,6 \%$ dos estudantes se consideram pessoas saudáveis, $81,6 \%$ referi- 
ram sentir cansaço (em algum lugar do corpo), moleza $(55,1 \%)$ sonolência diurna $(46,3 \%)$, e dores no corpo $(62,2 \%)$. Os locais mais referidos de dor são múltiplas localizações (46\%), coluna (18\%), membros superiores (10\%) e membros inferiores (12\%). Analisando especificamente os membros superiores e inferiores, $22 \%$ adolescentes referiram sentir dor apenas nesta localização e $26 \%$ a referiram associada a outras local izações, o que dá uma prevalência de $48 \%$ de referência de dor nos membros superiores e inferiores, entre a população de estudo. A penas 34\% dos adolescentes não referiram nenhum tipo de dor.

\section{Características ocupacionais}

À época da coleta de dados, 184 estudantes responderam ser trabalhadores, 85 informaram estar desempregados e 85 se declararam não trabalhadores.

Os principais postos de trabal ho foram: em escritórios e bancos (40,8\%), comércio em loja, farmácia e banca de jornal (14,1\%); em supermercado, açougue, quitanda e feira (6\%); bar, padaria, lanchonete e restaurante $(7,1 \%)$ e em casa (6,5\%). As funções mais exercidas foram balconista ( $16,8 \%)$, auxiliar administrativo, marketing, financeiro (11,4\%), ajudante geral $(11,4 \%)$, recepcionista, secretária $(12 \%)$ e "Office" boy (14,7\%). Entre os adolescentes trabal hadores e desempregados, $28,5 \%$ referiram jornadas diárias acima de 8 horas; $43,7 \%$ dos respondentes relataram jornadas semanais acima de 40 horas.

\section{Fatores de risco associados à menor duração de sono}

Os dados de sono aqui apresentados se baseiam em duas fontes: a referência da duração de sono nos dias da semana $(n=354)$. A comparação de médias de duração de sono segundo variáveis sociodemográficas, de estilo de vida e de trabal ho para todos os estudantes mostrou que houve diferenças estatisticamente significativas entre as médias de duração de sono e série e trabalho. Q uem estuda na la série re latou maior duração de sono do que quem está na 3a série do ensino médio (496,7 min e 447,3 min respectivamente) $(p=0,005)$. 0 s adolescentes que trabalham possuem, em média, menor duração de sono do que aqueles que não estão trabalhando $(440,7$ min e 516,4 min respectivamente) $(p<0,001)$.
Entre os adolescentes que trabal ham, houve associações significativas entre os adolescentes que relataram menor duração de sono e: ser do sexo masculino, estudar na 2a ou 3a série do ensino médio e os que referem sentir sono no trabal ho e nas aulas (Tabela 1). Em relação às variáveis de controle no trabal ho, os adolescentes que relataram maior duração de sono, em média, são aqueles que: possuem menor exigência psicológica no trabalho e menor insegurança no trabalho.

Analisando as variáveis relativas ao ambiente de trabalho, observa-se que os adolescentes que relataram maior duração de sono, em média, foram: os que trabal ham em casa, comparados aos que trabalham no comércio (Iojas ou supermercado, etc.), os que referem ganhar até 1 salário mínimo por mês, comparados à aqueles que referem ganhar entre $1,1 \mathrm{a}$ 2,0 SM ou mais que $2 \mathrm{SM}$. Em relação à jornada de trabalho diária, os adolescentes que trabalham menos do que 6 horas diárias relataram maior duração de sono do que os demais, o mesmo acontecendo com aqueles que trabaIham menos que 20 horas semanais. Por último, quando se anal isam as condições do ambiente de trabalho, verifica-se que os adolescentes que referem que seu local de trabalho é barulhento e existem gases evapores relataram menor duração de sono, em média.

\section{Conteúdo e estrutura da representação social do trabalho e da relação trabalho-estudo}

$\mathrm{Na}$ tabela 2 são mostrados os elementos centrais e periféricos da representação do trabalho analisada a partir das evocações aos termos Trabalhar e Estudar.

No conjunto da análise, e também no núcleo central, observa-se que as referências negativas associadas à dupla jornada, representada pelas atividades de trabal ho e estudo, foram as mais freqüentes. 0 grupo evocou palavras que apontam as dificuldades enfrentadas pelos jovens tais como "cansativo", "difícil", "necessidade", "muita responsabilidade", "estressante", "ruim", "correria" e "conciliar".

Destaca-se no núcleo central, presente no quadrante superior esquerdo, a palavra "necessidade" que expressa uma condição estrutural de base que condiciona a opção de muitos jovens para a concomitância do trabalho com 0 estudo, apontando para o trabal ho como fonte complementar dos recursos familiares necessá- 
Tabela 1

Estatística descritiva da duração média de sono para os adolescentes que trabalham, segundo variáveis sociodemográficas, de saúde e de trabalho.

\begin{tabular}{|c|c|c|c|c|c|}
\hline Variável & Categoria & $\mathbf{n}$ & média (dp*) & $\min -\max$ & $\mathrm{p}^{* *}$ \\
\hline Sexo & $\begin{array}{l}\text { Masculino } \\
\text { Feminino }\end{array}$ & $\begin{array}{r}101 \\
83\end{array}$ & $\begin{array}{l}429,9(102,4) \\
469,1(118,0)\end{array}$ & $\begin{array}{l}240-720 \\
240-720\end{array}$ & $<0,01 t$ \\
\hline Série & 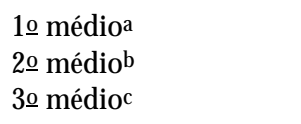 & $\begin{array}{l}73 \\
57 \\
54\end{array}$ & $\begin{array}{r}469,0(123,5) \\
438,2(104,4) \\
431,0(98,4)\end{array}$ & $\begin{array}{l}240-720 \\
240-660 \\
250-660\end{array}$ & $\begin{array}{r}0,05 A \\
(a \neq b, c)\end{array}$ \\
\hline Sono no trabalho & $\begin{array}{l}\text { não } \\
\text { sim }\end{array}$ & $\begin{array}{r}162 \\
21\end{array}$ & $\begin{array}{r}446,7(110,0) \\
397,1(76,1)\end{array}$ & $\begin{array}{l}240-720 \\
300-570\end{array}$ & $0,013 \mathrm{t}$ \\
\hline Sono nas aulas & $\begin{array}{l}\text { nãoa } \\
\text { simb } \\
\text { às vezesc }\end{array}$ & $\begin{array}{l}54 \\
32 \\
98\end{array}$ & $\begin{array}{r}479,4(115,6) \\
381,3(84,8) \\
439,4(100,7)\end{array}$ & $\begin{array}{l}240-720 \\
240-600 \\
270-720\end{array}$ & $\begin{array}{c}<0,001 A \\
(a \neq b ; p=0,050) \\
(b \neq c ; p=0,050)\end{array}$ \\
\hline $\begin{array}{l}\text { Exigências psicológicas } \\
\text { no trabalho*** }\end{array}$ & $\begin{array}{l}18-28 a \\
29-32 b \\
33-48 c\end{array}$ & $\begin{array}{l}68 \\
59 \\
57\end{array}$ & $\begin{array}{r}463,1(113,1) \\
449,3(104,3) \\
404,9(95,6)\end{array}$ & $\begin{array}{l}250-720 \\
270-660 \\
240-720\end{array}$ & $\begin{array}{c}0,007 A \\
(a \neq c ; p=0,050)\end{array}$ \\
\hline $\begin{array}{l}\text { Insegurança } \\
\text { no trabalho*** }\end{array}$ & $\begin{array}{l}3-4 a \\
5-11 b \\
12-22 c\end{array}$ & $\begin{array}{l}72 \\
95 \\
17\end{array}$ & $\begin{array}{l}423,4(102,4) \\
441,9(106,0) \\
506,8(115,9)\end{array}$ & $\begin{array}{l}240-720 \\
240-720 \\
330-720\end{array}$ & $\begin{array}{c}0,015 A \\
(a \neq c ; p=0,050)\end{array}$ \\
\hline Local de trabalho & $\begin{array}{l}\text { serviçosa } \\
\text { comércio (lojas)b }^{\text {b }} \\
\text { comércio (alimentos)c } \\
\text { comércio (bebidas)d } \\
\text { na residênciae } \\
\text { outrosf }^{\text {che }}\end{array}$ & $\begin{array}{l}75 \\
26 \\
11 \\
13 \\
12 \\
47\end{array}$ & $\begin{array}{r}452,9(109,2) \\
409,6(78,9) \\
401,8(100,6) \\
425,8(104,9) \\
527,1(115,9) \\
429,5(108,4)\end{array}$ & $\begin{array}{l}240-720 \\
250-540 \\
300-660 \\
315-720 \\
360-720 \\
240-630\end{array}$ & $\begin{array}{c}0,020 A \\
(e>b, c, e ; p=0,050)\end{array}$ \\
\hline $\begin{array}{l}\text { Salário mensal } \\
\text { (em SM) }\end{array}$ & $\begin{array}{l}\text { nada }(0) \text { a } \\
\text { até } 1,0 \text { SM b } \\
1,1-2,0 \text { SM c } \\
2,1 \text { e }+ \text { SM d }\end{array}$ & $\begin{array}{l}17 \\
32 \\
91 \\
44\end{array}$ & $\begin{array}{r}487,4(108,3) \\
489,1(121,6) \\
424,8(100,6) \\
420,2(96,5)\end{array}$ & $\begin{array}{l}315-720 \\
330-720 \\
240-720 \\
240-630\end{array}$ & $\begin{array}{c}0,003 A \\
(b>c, d ; p=0,050)\end{array}$ \\
\hline Jornada diária & $\begin{array}{l}\text { até } 6,0 \text { horasa } \\
6,1-8,0 \text { horasb } \\
8,1 \text { e }+ \text { horasc }\end{array}$ & $\begin{array}{l}53 \\
65 \\
63\end{array}$ & $\begin{array}{r}496,5(104,2) \\
422,8(106,7) \\
404,0(86,1)\end{array}$ & $\begin{array}{l}240-720 \\
240-720 \\
300-660\end{array}$ & $\begin{array}{c}<0,001 A \\
(a<b, c ; p<0,05)\end{array}$ \\
\hline Jornada semanal & $\begin{array}{l}\text { até } 20,0 \text { horasa } \\
20,1-30,0 \text { h.b } \\
30,1-40,0 \text { h.c } \\
40,1-50,0 \text { hd } \\
50,1 \text { e }+ \text { horase }\end{array}$ & $\begin{array}{l}23 \\
19 \\
54 \\
68 \\
17\end{array}$ & $\begin{array}{r}512,0(99,7) \\
462,9(89,9) \\
438,7(109,9) \\
412,5(101,3) \\
408,2(91,2)\end{array}$ & $\begin{array}{l}360-720 \\
300-630 \\
240-720 \\
240-720 \\
300-630\end{array}$ & $\begin{array}{c}0,001 \mathrm{~A} \\
(a<c, d, e ; p<0,05)\end{array}$ \\
\hline Ambiente barulhento & $\begin{array}{l}\text { não } \\
\text { sim }\end{array}$ & $\begin{array}{r}118 \\
66\end{array}$ & $\begin{array}{r}457,4(112,2) \\
410,7(91,8)\end{array}$ & $\begin{array}{l}240-720 \\
240-660\end{array}$ & $0,003 \mathrm{t}$ \\
\hline $\begin{array}{l}\text { Ambiente com } \\
\text { gases e vapores }\end{array}$ & $\begin{array}{l}\text { não } \\
\text { sim }\end{array}$ & $\begin{array}{r}146 \\
38\end{array}$ & $\begin{array}{r}450,7(111,3) \\
402,0(81,4)\end{array}$ & $\begin{array}{l}240-720 \\
300-660\end{array}$ & $0,003 \mathrm{t}$ \\
\hline
\end{tabular}

*dp: desvio padrão

*t* - nível descritivo do teste t-Student; A: análise de variância a um fator ***em tercis 
Tabela 2

Estrutura da representação social do trabal ho a partir do termo indutor "trabalhar e estudar" no grupo de estudantes do período noturno, pela freqüência média e pela ordem média de evocação (OME). São Paulo, 2002.

\begin{tabular}{|c|c|c|c|c|c|c|}
\hline O.M.E & $<2,8$ & & & Ž2,8 & & \\
\hline Freqüência & & Freq. & OME & & Freq. & $\mathrm{OME}$ \\
\hline \multirow[t]{5}{*}{$\geq \mathbf{4 4}$} & Cansativo & 215 & 2,0 & Futuro & 66 & 3,2 \\
\hline & Difícil & 75 & 2,0 & $\begin{array}{l}\text { Muita } \\
\text { responsabilidade }\end{array}$ & 62 & 3,0 \\
\hline & Bom & 55 & 2,7 & Estressante & 46 & 3,0 \\
\hline & Necessidade & 55 & 2,6 & & & \\
\hline & Esforço & 54 & 2,3 & & & \\
\hline Freqüência & & Freq. & OME & & Freq. & $\mathrm{OME}$ \\
\hline \multirow[t]{9}{*}{$<44$} & Essencial & 42 & 2,5 & Falta de tempo & 34 & 3,2 \\
\hline & Responsável & 33 & 2,2 & Atrapalha o estudo & 33 & 3,0 \\
\hline & Ruim & 32 & 2,5 & Sono & 27 & 3,1 \\
\hline & Correria & 25 & 2,3 & Aprender & 26 & 3,0 \\
\hline & Estudar & 22 & 2,6 & Acordar cedo & 24 & 3,1 \\
\hline & Conciliar & 20 & 2,7 & Amadurecimento & 24 & 3,5 \\
\hline & & & & Força de vontade & 24 & 2,9 \\
\hline & & & & Relacionamento & 18 & 3,6 \\
\hline & & & & Tempo & 17 & 3,0 \\
\hline
\end{tabular}

rios à sobrevivência. No trabalho desenvolvido por Pinheiro (1999), a necessidade econômica aparece como justificativa para o trabal ho para $39 \%$ da população de jovens estudados, seguida pela independência financeira com $31,2 \%$, e em terceiro lugar os motivos ligados ao prazer de trabalhar, ao amadurecimento e perspectivas de um futuro melhor.

A palavra "bom" expressa um sentido simbólico positivo e remete à dimensão moral do trabalho, na qual são expressos os valores que enaltecem o trabal ho em quaisquer circunstâncias negando os seus efeitos negativos, como um ideal moral do homem, portanto determinado social mente. Tradicionalmente o trabaIho tem sido visto a partir de uma expressão moral, como bom, nobre, dentre outros atributos, o que parece determinar 0 aparecimento dessa evocação. A palavra "esforço" denota, ao mesmo tempo, um atributo pessoal necessário para suportar a dupla jornada, e a reafirmação da dureza da concomitância dessas atividades. Autores como Mielnik (1987) e Pinheiro (1999) referem os baixos salários, poucas horas de sono, menor tempo para recreação e lazer, redução do tempo para o estudo, dificuldades para se alimentar e desinteresse pelo estudo como conseqüências da dupla jornada trabalho- estudo. Finalmente, essa representação é estruturada a partir dos termos "cansativo" e "difícil", que expressam a sobrecarga da concomitância do trabalho com o estudo.

Os elementos periféricos próximos - quadrante superior direito e inferior esquerdo denotam um conteúdo positivo da representação, a partir das evocações "futuro", "essencial", "responsável", mas também negativo, presente nos termos "muita responsabilidade", "estressante", "ruim", "correria", "estudar" e"conciliar".

A positividade da dupla jornada relacionase à crença em ganhos psicossociais e de que os méritos pessoais possibilitam superar as dificuldades derivadas das duas atividades, além de ser representado como necessário e honroso, por dar mostras da capacidade de luta e determinação dos jovens. A palavra "futuro" foi evocada como um desses el ementos positivos, retratando a crença de que o trabalho precoce pode assegurar experiência profissional que permita melhor qualidade de vida e a superação da condição de classe ocupada pelos adolescentes. As evocações "muita responsabilidade" e "estressante" refletem a falta de experiência no trabalho, o excesso de tar efas e, especialmente, exigências psicossociais incompatíveis com o momento de desenvolvimento do jovem 
trabal hador, como por exemplo, a concorrência implícita ao trabalho, o estabelecimento de relações interpessoais diversificadas e motivadas por relações de poder e diversificados interesses, dentre outras.

$\mathrm{N}$ a periferia distante - quadrante inferior direito - podem ser observados termos positivos e negativos, reafirmando a contradição presente na representação do trabalho. A positividade foi expressa nos vocábulos "aprender", "amadurecimento", "relacionamento" e "força de vontade" e relaciona-se ao crescimento pessoal e ao conteúdo pedagógico do trabalho. A negatividade nas palavras "falta de tempo", "atrapal ha o estudo", "sono" e "acordar cedo" manifestou-se na indicação das formas como o trabalho e o estudo executados numa mesma jornada de 24 horas afetam a saúde e o desempenho escolar.

Destacando os agravos à saúde, as evocações "sono", "acordar cedo", "falta de tempo" e "tempo" expressam o reconhecimento da incompatibilidade da concomitância trabal ho e estudo, nos moldes como vem sendo desenvolvido em países como o Brasil, de forma competitiva e não educativa. Por sua vez, as evocações "aprender", "amadurecimento", "relacionamento" e "força de vontade" representam 0 trabal ho a partir dos ganhos a longo prazo, como preparação para a vida e para o mercado de trabal ho, presentes nas referências às funções do trabal ho relacionadas à criatividade e ao futuro profissional. N esse aspecto deve-se destacar que, embora a evocação "aprender" faça pensar numa atividade que gera aprendizado, a realidade observada na descrição das características ocupacionais da amostra estudada não sustenta essas afirmações. As funções ocupadas pelos jovens refletem atividades repetitivas e sem nenhum grau de especialização, como balconista, auxiliar administrativo e ajudante geral.

Para integrar a discussão geral da representação da relação trabalho-estudo sugere-se refletir sobre as observações de Flament (2001): $\mathrm{N}$ a realidade, a periferia da representação serve de pára-choque entre uma realidade que a questiona e um núcleo central que não deve mudar facilmente. Os desacordos da realidade são absorvidos pelos esquemas periféricos que, assim, asseguram a estabilidade (relativa) da representação.

Essa função de pára-choque, destacada por Flament, pode ser observada na presença de evocações positivas e negativas no último qua- drante. Parece que esses esquemas não entraram em antagonismo entre os jovens estudados, a ponto de mudar a representação do trabalho. Os el ementos periféricos apresentados suportam as múltiplas discordâncias da alternância do trabalho com o estudo, por um lado, porque 0 trabal ho contribui para 0 amadurecimento pessoal, possibilita novas experiências e a independência econômica; e, por outro, porque causa danos à saúde, gera aborrecimentos, representa uma obrigação, e compete com 0 tempo destinado ao estudo e ao lazer.

Cabe apontar que, nos dados observados, é a prática social dos adolescentes que desencadeia as representações sociais, uma vez que 0 grupo analisado é formado, na sua quase totalidade, por jovens trabalhadores. Daí a importância do contexto social no qual esses jovens estão inseridos, onde predomina a necessidade econômica e a contribuição necessária para a renda familiar, como já descrito no trabal ho de Kinney (1993).

N este trabalho, a verificação da hipótese de centralidade foi realizada com a análise de similitude, que será apresentada na figura 1.

$\mathrm{Na}$ figura 1 observa-se que a categoria "cansativo" é aquela que organiza a representação do trabalho quando vista a partir da relação trabal ho-estudo, denotando os prejuízos e dificuldades causados pelo trabalho. As ligações mais fortes observadas nessa figura expressam significados negativos da relação trabalho-estudo, presente nas categorias "perdas", "difícil", "necessidade" e "tempo". Essas categorias dão o significado primeiro da representação para os jovens estudados, reforçando e especificando a análise dos quadrantes apresentada na tabela 2.

As ligações menos fortes são expressas pelas categorias "relacionamento", "determinação" e "dinheiro" expressando o caráter subordinado desses significados na representação analisada.

O conjunto dos elementos presentes na re presentação social do trabalho quando analisada a partir da relação trabalho-estudo pode ser melhor compreendido levando-se em conta sua organização em torno de três dimensões: dimensão prática; dimensão econômica e dimensão psicossocial.

A dimensão prática expressa as conseqüências negativas do trabal ho através das categorias "difícil", "perdas" e "tempo". O bserva-se, ainda, a presença das categorias "estudar" e "depende" apontando para a opção pelo estudo, ou pela dúvida nas situações de escolha entre o trabalho e o estudo. 


\section{Figura 1}

Estrutura da representação social de Trabalhar e Estudar no grupo de estudantes do ensino noturno resultante da análise de similitude. São Paulo, 2002.

Trabalhar eEstudar

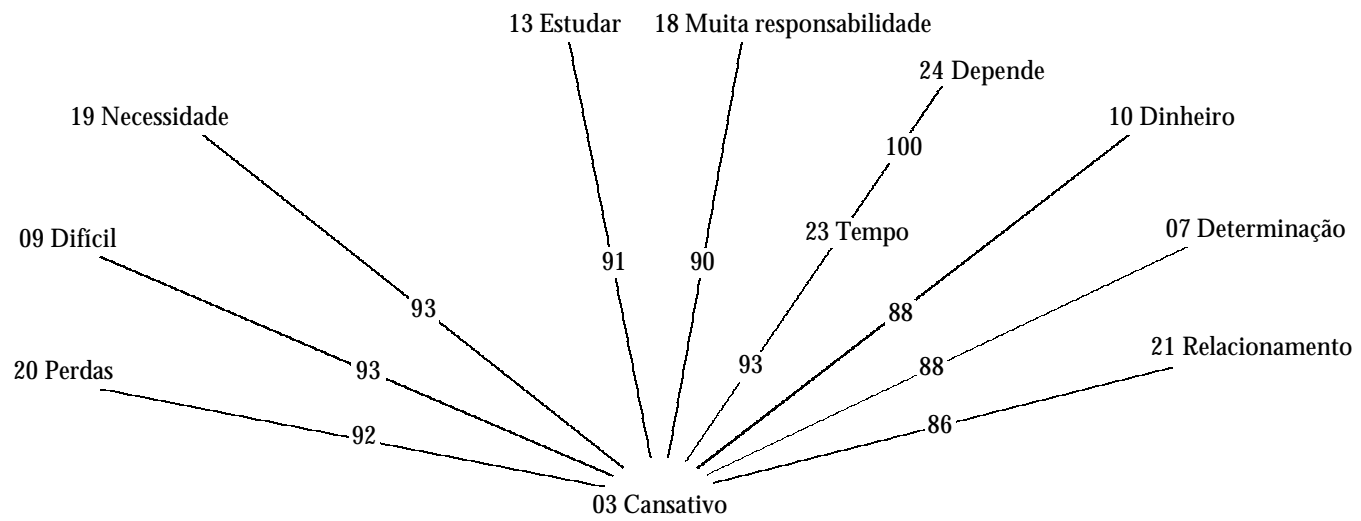

A dimensão psicossocial remete aos ganhos e perdas para o desenvolvimento do jovem trabalhador, representando, por um lado, as dificuldades enfrentadas pelos jovens na dupla jornada trabalho-estudo e, por outro, as suas conseqüências para a formação da auto-imagem e da identidade, como se o trabal ho possibilitasse a agilização do desenvolvimento ao permitir uma maior identificação com o adulto, presente na categoria "muita responsabilidade", "relacionamento" e "determinação".

A dimensão econômica é coadjuvante na análise da representação da relação trabalhoestudo. Expressa não só os ben efícios econômicos do trabalho, mas especialmente a necessidade econômica que o determina, e é manifesta nas categorias "dinheiro" e "necessidade".

\section{Discussão e conclusões}

Se perguntarmos quais são as atividades que os adolescentes mais apreciam, dormir será uma delas. Estudos conduzidos por autores brasileiros ( $M$ achado et al, 1998; Vinha et al, 2002; Teixeira, 2002) mostraram que a duração de sono entre adolescentes fica prejudicada quando têm de acordar muito cedo para ir à escola, ou ir trabalhar. A associação entre trabalho e redução de sono foi observada neste estudo.
Acordar mais cedo e a menor duração do sono indicam que o horário de trabalho atua como potente sincronizador e/ou mascarador do ciclo vigília-sono em adolescentes. 0 fato de ter que trabalhar durante o dia obriga o estudante a acordar mais cedo e isso contribui para a privação parcial de sono, devido à diminuição da duração do sono noturno. As conseqüências da privação parcial do sono noturno durante os dias de semana podem ser verificadas a partir da maior dificuldade para acordar e da menor qualidade do sono, e são destacadas nas representações dos jovens.

Fischer et al. (2000), ao analisarem a duração de sono de adolescentes trabalhadores e não trabalhadores do interior de São Paulo, constataram que a menor duração de sono estava associada aos estudantes trabalhadores que têm jornada integral de trabal ho, sentem sono durante o trabalho e nas aulas, e percebem a qualidade do local de trabalho como pior. No presente estudo, a menor duração de sono também foi associada aos estudantes trabalhadores que trabalham em locais e funções com maiores exigências (físicas e mentais), que enfrentam condições desfavoráveis relativas à falta de controle no trabal ho, que trabalham em locais insalubres. U m dos efeitos conhecidos do ruído, além de provocar perdas auditivas, é o de perturbar o sono: os trabal hadores 
que estão em locais ruidosos têm mais distúrbios de sono e dormem menos (Rutenfranz, Knauth \& Fischer, 1989).

Os efeitos da redução de sono se fazem sentir no trabal ho e durante as aulas: quem dorme menos tem maior sonolência. N este estudo verificamos que mesmo em locais onde aparentemente as atividades são "leves", tais como escritórios, bancos, foi observada redução da média de sono diário.

U ma importante parcela dos estudantes avaliados nesta pesquisa exercia jornadas de trabalho superiores a oito horas diárias, o que certamente restringe ou torna difícil conciliar o trabalho com o estudo.

A representação social observada revela algumas facetas que cumprem a função de justificar o trabal ho e a sobrecarga representada pela concomitância trabal ho-estudo. Para os jovens estudados, o trabal ho nas condições observadas exige uma justificativa plausível que dê significado à continuidade do mesmo. Apesar de realista, a justificação funciona como um "amortecedor" psicológico que contribui para a permanência do trabalho em quaisquer condições. Essa função justificatória, no entanto, não é suficiente para anular a ambivalência diante do trabalho, resultando em imagem negativa que ancora a relação trabal ho- estudo no cansaço e no estresse físico e psicológico. No entanto, essa sobrecarga é aceita como inevitável para a construção de um futuro diferente daquele das famílias de origem dos jovens, e que pode ser superada através do maior empenho, uma vez que traz recompensas a longo prazo que justificam o seu enfrentamento.

Como conclusões da análise das representações sociais do trabalho pode-se afirmar que essas representações apontam para uma contradição entre o reconhecimento do trabalho como valor moral, positivo para o desenvolvimento psicossocial e a constituição da identidade, e os problemas que decorrem de uma carga física e psicológica precoce. Os comprometimentos para a saúde fazem parte dessa representação, ora se apresentando em forma de autocul pabilização, ora associados às condições de trabalho e à privação do sono.

Esses resultados trazem implicações importantes para as práticas de cuidados dirigidas aos jovens trabalhadores, uma vez que apontam para imagens específicas desse grupo populacional que merecem ser consideradas nas práticas educativas e no planejamento das ações de saúde a eles dirigidas.
A visão ingênua de associar apenas a expe riência profissional a uma melhor inserção no mercado de trabalho ea um melhor futuro pode e deve ser desmistificada entre os jovens, no sentido de evitar a sua saída precoce da escola (motivada apenas por essa crença), e também de prevenir os agravos à saúde decorrentes da sobrecarga trabal ho-estudo.

As relações existentes entre o trabalho, a escola, a privação de sono e a sonolência diurna são assuntos de grande interesse para professores, pedagogos e outros profissionais envolvidos na educação, pois há um esforço coletivo para a melhoria das condições de aprendizado. A partir do momento em que todos estão cientes desses problemas, as preocupações mais freqüentes voltam-se para os prejuízos ao desempenho escolar, devido à menor concentração, menor vigilância e atenção, e lapsos de memória. Soma-se a estes aspectos o reduzido tempo de permanência na escola, a impossibilidade de dedicar-se aos estudos fora do horário escolar, as freqüentes ausências e atrasos às aulas e a evasão escolar.

Este estudo sugere a necessidade de interven ção na organização social, principalmente na organização escolar. Alterações nos horários escolares, como por exemplo, aulas aos sábados para os estudantes trabal hadores e início mais tardio das aulas no período noturno, são importantes para o melhor aproveitamento escolar. As mudanças devem priorizar as necessidades de sono desses estudantes, mas não podem esquecer as comunidades (profissionais da área de educação, pais, etc) que estão envolvidas.

Além da intervenção na organização escolar, são necessários treinamentos gerais e especializados, que garantam aos adolescentes a realização de atividades que de fato Ihes tragam benefícios palpáveis, mais que o de apenas receberem miseráveis pagamentos para sua sobrevivência e, por vezes, a de sua família. Acredita-se que, perante os resultados da pesquisa, a escola poderá se tornar um fator importante na difícil tarefa de tentar resgatar o papel da família na vida dos adolescentes trabal hadores.

Há necessidade de se implantar cursos de preparação para o trabalho, principalmente no ensino médio, no qual faltam: materiais didáticos e disciplinas específicas; professores que se dediquem a explorar o tema em sala de aula; reuniões onde os principais atores interessados possam ativamente participar e dirimir dúvidas; conselheiros escolares (pedagogos, psicólogos, médicos e outros profissionais da saúde) 
para atenderem os adolescentes, e ajudá-los na difícil tarefa de promover a saúde, e de conhecimentos específicos que lhes permitam proteger sua saúde e desenvolver-se plenamente, como prevê a Constituição Brasileira e os Direitos Humanos.

\section{Agradecimentos}

FAPESP e CN Pq pelo apoio financeiro; aos demais membros da equipe de trabalho: M arcio Lombardi Jr (bolsista de Iniciação Científica FAPESP); Roberta Nagai (bolsista de Treinamento Técnico FAPESP); prof. dr. Celso Pereira de Sá, do Instituto de Psicologia da UERJ; profạ drạM aria do Rosário Dias de Oliveira Latorre, do Departamento de Epidemiologia da Faculdade de Saúde Pública da USP; e dra Sharon Cooper, da A\& M U niversity System, Texas, USA (consultores das análises de representações sociais, estatística e epidemiologia).

\section{Referências bibliográficas}

Abreu SR 2002. Crianças e adolescentes em situações de risco no Brasil. Revista Brasileira de Psiquiatria 24 (1):5-6.

Abric JC 1994. Pratiques sociales et représentations. Presses Universitaires de France, Paris.

Andrade M M M \& M enna-Barreto L 1996. Diurnal variation in oral temperature, sleepiness and performance of high school girls. Biological Rhythm Research 27 (3): 336-342.

Andrade M M M 1997. Padrões temporais das expressões da sonolência em adolescentes Tese de doutorado. Instituto de Ciências Biomédicas, USP, São Paulo.

Fischer FM \& Oliveira DC 2003a. Condições de vida e trabalho de estudantes do ensino médio no município de São Paulo. Relatório Técnico disponível. Faculdade de Saúde Pública da USP.

Fischer FM et al. 2003b. Occupational accidents among middle and high school students in small towns of São Paulo State, Brazil. Revista Saúde Pública 37 (3):351-356.

Fischer FM , M artins IS \& Oliveira DC 2000. Relatório final do projeto: saúde, educação e trabalho nos municípios de M onteiro Lobato e Santo Antônio do Pinhal, SP. Volume III. Faculdade de Saúde Pública da USP, São Paulo.

Flament C 1994. Structure, dynamique et transformation des representations sociales, pp. 37-57. In JC Abric. Pratiques sociales et représentations. Presses U niversitaires de France, Paris.
Flament C 2001. Estrutura e dinâmica das representações sociais, pp.173-186. In D Jodelet (org.). As representações sociais. EDUERJ, Rio de Janeiro.

Forastieri V 1997. Children at work. Health and safety risks. ILO Office, Geneva.

Fundação IBGE 2000. Censo Demográfico. 2000. São Paulo. Jodelet D 1989. Folies et représentations sociales. PUF, Paris.

Karasek RA et al. 1985. The Job content questionnaire (JCQ): an instrument for internationally comparative assessments of psychosocial job characteristics. Journal Occupational Health Psychology 3(4):322355.

Kassouf AL, M ckee M \& M ossialos E 2001. Early entrance to the job market and its effect on adult health: evidence from Brazil. Health Policy and Planning 16 (1):21-28

Kinney JA 1993. Health hazards to children in the service industries. American Journal of Industrial M edicine 24:291-300.

Lack L 1986. Delayed sleep and sleep loss in U niversity students. Journal American College H ealth 35:105110.

M achado ERS, Varella VBR \& Andrade M M M 1998. The influence of study's schedule and work on the sleepwake cycle of college students. Biological Rhythm Research 29:578-584.

M ielnik I 1987. 0 adolescente, a escola e o trabalho. Pediatria M oderna 23(8):278-291. 
M oscovici S 1978. A representação social da psicanálise. Ed. Zahar, Rio de Janeiro.

$\mathrm{N}$ ational Institute for Occupational Safety and $\mathrm{H}$ ealth (NIOSH) 1997. Child labor research needs. Recommendations from N IOSH child labor working team. (DHHS-NIOSH publication № 97-143).

Oliveira DC 1996. A promoção da saúde da criança: análise das práticas cotidianas através dos estudos de representações sociais. Tese de doutorado. Faculdade de Saúde Pública da USP, São Paulo.

Oliveira DC, Fischer FM , M artins IS, Teixeira LR \& Sá CP 2001. Futuro e liberdade: o trabalho e a instituição escolar nas representações sociais de adolescentes. Revista Estudos de Psicologia, N atal 6(2):245-258.

Parker D 1997. Health effects of child labour. The Lancet 35:1.395-1.396.

Pinheiro AB 1999. 0 trabalho precoce em adolescentes matriculados em escolas municipais da Zona Sul do Rio de Janeiro. Tese de doutorado. Escola Nacional de Saúde Pública, Fiocruz, M inistério da Saúde, Rio de Janeiro.
Rutenfranz J, Knauth P \& Fischer FM 1989. Trabalho em turnos e noturno. Hucitec, São Paulo.

Sá CP 1996. Núcleo Central das Representações Sociais. Vozes, Petrópolis.

Sá CP 1998. A construção do objeto de pesquisa em representações sociais. Editora da U erj, Rio de Janeiro.

Teixeira LR 2002. Análise dos padrões do ciclo vigília-sono de adolescentes trabalhadores e não trabalhadores, alunos de escola pública no município de São Paulo. Dissertação de mestrado. Faculdade de Saúde Pública, USP. São Paulo.

Vergès $P$ 2000. Ensemble de programmes permettant $I^{\prime}$ analyse des evocations: M anuel versoin 2.00.. Laboratoire M éditerranée en Sociologie, Aix-en-Provence

Vinha D, Cavalcante JA \& Andrade M M M 2002. Sleepwake patterns of student workers and non-workers. Biological Rhythm Research 33(4):417-426.

Artigo apresentado em 15/8/2003

Aprovado em 16/10/2003

Versão final apresentada em 26/11/2003 